\title{
Trocas gasosas e eficiência fotoquímica de cultivares de algodoeiro herbáceo sob aplicação de silício foliar
}

\section{Gas exchange and photochemical efficiency of cotton cultivars under leaf application of silicon}

\author{
Rener Luciano de Souza Ferraz ${ }^{1 *}$; Napoleão Esberard de Macêdo Beltrão ${ }^{2}$; \\ Alberto Soares de $\mathrm{Melo}^{3}$; Ivomberg Dourado Magalhães ${ }^{4}$; \\ Pedro Dantas Fernandes ${ }^{5}$; Maria do Socorro Rocha ${ }^{6}$
}

\section{Resumo}

Objetivou-se com este trabalho avaliar as trocas gasosas e a eficiência fotoquímica de cultivares de algodoeiro sob aplicação de silício foliar. Para tanto, conduziu-se experimento em delineamento inteiramente casualizado em esquema fatorial 3 x 5, sendo três cultivares de algodoeiro ('BRS Topázio', 'BRS Safira' e 'BRS Rubi'), cinco doses de silício (0, 50, 100, 150, $\left.200 \mathrm{mg} \mathrm{L}^{-1}\right)$ e quatro repetições. As trocas gasosas e eficiência fotoquímica foram determinadas a partir da mensuração da taxa assimilação de $\mathrm{CO}_{2}$, transpiração, condutância estomática, concentração interna de $\mathrm{CO}_{2}$, eficiência instantânea no uso da água, eficiência instantânea da carboxilação, fluorescência inicial, máxima, variável e eficiência quântica do fotossistema II (FSII). Os dados das variáveis foram submetidos à análise de variância, regressão e teste de comparação de médias. Houve diferenças significativas para trocas gasosas e eficiência fotoquímica em resposta às concentrações de silício. Também foram constatadas diferenças significativas entre as cultivares de algodoeiro avaliadas. Na cultivar 'BRS Topázio', a aplicação de silício aumentou a taxa de assimilação de $\mathrm{CO}_{2}$ e eficiência quântica do FSII. Na 'BRS Safira' o silício reduziu a taxa de assimilação e concentração interna de $\mathrm{CO}_{2}$. Na 'BRS Rubi' o elemento aumentou a fluorescência da clorofila 'a' e eficiência quântica do fotossistema II e, reduziu a taxa de assimilação e concentração interna de $\mathrm{CO}_{2}$ e condutância estomática. A adubação silicatada propiciou à 'BRS Topázio' expressar melhor taxa fotossintética em relação às 'BRS Safira' e 'BRS Rubi. Não ocorreu dano no FSII quando as cultivares 'BRS Topázio', 'BRS Safira' e 'BRS Rubi” receberam nutrição suplementar de silício.

Palavras-chave: Gossypium hirsutum L., nutrição foliar, fotossíntese, silicato de potássio

\footnotetext{
Abstract

The objective of this study was to evaluate gas exchange and photochemical efficiency of cotton cultivars under leaf application of silicon. Therefore, the experiment was conducted in a completely randomized in a factorial $3 \times 5$, three cotton cultivars ('BRS Topázio', 'BRS Safira' and 'BRS Rubi'), five silicon concentrations $\left(0,50,100,150,200 \mathrm{mg} \mathrm{L}^{-1}\right)$ and four replications. Gas exchange and photochemical efficiency were determined by measuring the rate of $\mathrm{CO}_{2}$ assimilation, transpiration,

1 Discente de Doutorado em Agronomia, Produção Vegetal, Universidade Estadual Paulista, UNESP, Jaboticabal, SP. E-mail: ferraz340@gmail.com

2 In memoriam, Pesquisador, Empresa Brasileira de Pesquisa Agropecuária, EMBRAPA, Campina Grande, PB. E-mail: chgeral@ cnpa.embrapa.br

3 Prof. Dr. da Universidade Estadual da Paraíba, UEPB, Campina Grande, PB. E-mail: alberto@uepb.edu.br

4 M.e em Ciências Agrárias, UEPB, Campina Grande, PB. E-mail: ivomberg31@hotmail.com

5 Prof. Dr. da Universidade Federal de Campina Grande, UFCG, Campina Grande, PB. E-mail: pdantas@pq.cnpq.br

6 Pós Dr ${ }^{\mathrm{a}}$ em Agronomia, UEPB, Areia, PB. E-mail: marialirium@hotmail.com

Autor para correspondência
} 
stomatal conductance, internal $\mathrm{CO}_{2}$ concentration, instantaneous efficiency in water use, instantaneous carboxylation efficiency, initial fluorescence, maximum quantum efficiency of the variable and photosystem II (PSII). The data variables were subjected to analysis of variance and regression test comparison of means. There were significant differences in gas exchange and photochemical efficiency in response to concentrations of silicon. There were also significant differences among cotton cultivars evaluated. In cultivar 'BRS Topázio', the application of silicon increased $\mathrm{CO}_{2}$ assimilation rate and quantum efficiency of PSII. In 'BRS Safira' silicon reduced the rate of assimilation and internal $\mathrm{CO}_{2}$ concentration. In 'BRS Rubi' element increased the fluorescence of chlorophyll ' $a$ ' and quantum efficiency of photosystem II, and reduced the rate of assimilation and internal $\mathrm{CO}_{2}$ concentration and stomatal conductance. Silicate fertilization provided 'BRS Topázio' to express better photosynthetic rate in relation to 'BRS Safira' and 'BRS Rubi'. No damage occurred in PSII when 'BRS Topázio', 'BRS Safira' and 'BRS Rubi' cultivars received silicon as supplementary nutrition.

Key words: Gossypium hirsutum L., leaf nutrition, photosynthesis, potassium silicate

\section{Introdução}

O algodoeiro herbáceo (Gossypium hirsutum L. r. latifolium Hutch.) é uma oleaginosa e fibrosa cultivada em mais 70 países em todo o mundo e desempenha um papel importante na economia global (DEEBA et al., 2012). Esta oleaginosa é uma das principais culturas exploradas no Brasil, onde este país ocupa a quinta colocação dentre os países produtores de algodão. Ressalte-se que a cotonicultura destaca-se no cenário nacional como cultura de expressiva importância para o agronegócio brasileiro (OLIVEIRA et al., 2012).

$\mathrm{Na}$ safra 2011/2012 a área cultivada com algodão no Brasil foi de 1.396,0 mil hectares, tendo a região Nordeste contribuído com $33 \%$ da área total. No estado da Paraíba foram cultivados 0,2 mil ha com esta cultura (CONAB, 2012). Acrescentese que no inicio de 2012, planejou-se cultivar no território paraibano cerca de 200 ha com algodão naturalmente colorido.

O potencial social, ambiental e econômico do algodão naturalmente colorido desenvolvido e cultivado na Paraíba é indiscutível. Porém, a cadeia produtiva necessita do emprego de tecnologias para ampliar a produção de algodão colorido (ABA, 2012). Uma alternativa viável para o incremento de produção da cultura é a utilização de cultivares de algodão de fibra colorida e ecoadaptadas às condições edafoclimáticas do semiárido.
Outra prática potencial para otimizar a cadeia produtiva do algodão é a aplicação de silício foliar, notadamente, em virtude de esse elemento ter sido associado a diversos efeitos indiretos. Por exemplo, destacam-se: ganho na capacidade fotossintética, redução da transpiração e aumento da resistência mecânica das células em plantas de rúcula (GUERRERO; BORGES; FERNANDES, 2011). Já Ferreira (2008) verificou ação positiva do silício em solução nutritiva sobre a fotossíntese, a transpiração, a condutância estomática e a concentração interna de $\mathrm{CO}_{2}$ do algodoeiro herbáceo 'BRS Cedro'.

Pesquisas envolvendo a fisiologia das plantas são importantes para subsidiar o desenvolvimento científico e tecnológico, notadamente, objetivando aumentar a eficiência do cultivo e incrementar a produção de algodão (OLIVEIRA et al., 2012). Acrescente-se que, a literatura acerca da utilização de silício foliar no algodoeiro é incipiente, sobretudo na região Semiárida do Nordeste brasileiro. Neste sentido, objetivou-se com este trabalho avaliar as trocas gasosas e a eficiência fotoquímica de cultivares de algodoeiro herbáceo sob aplicação de silício foliar.

\section{Material e Métodos}

O experimento foi conduzido no período compreendido entre os meses de setembro a dezembro de 2011, na área experimental da Embrapa 
Algodão, situada na microrregião de Campina Grande, PB, sob as coordenadas geográficas: $07^{\circ} 13^{\prime}$ de latitude Sul e $53^{\circ} 31^{\prime}$ de longitude Oeste. A cidade está situada a uma altitude de 551 metros, com clima equatorial semiárido e temperatura média de $25^{\circ} \mathrm{C}$, com umidade relativa do ar variando entre 72 e $91 \%$.
Diariamente foram coletadas as variáveis climáticas na estação agrometeorológica automatizada, localizada próximo ao local do experimento. Foram coletadas as variáveis: temperaturas máxima (T máx. $\left.{ }^{\circ} \mathrm{C}\right)$, mínima ( $\mathrm{T}$ min. ${ }^{\circ} \mathrm{C}$ ) e média (T méd. ${ }^{\circ} \mathrm{C}$ ) ambiental, umidade relativa do ar (URar \%) (Figura 1A), insolação diária (IND Horas), evaporação do tanque classe 'A' (ECA mm) e precipitação pluviométrica (PPL mm) (Figura 1B).

Figura 1. Variáveis climáticas registradas durante o período de condução do experimento. * Mensuração da fluorescência da clorofila 'a' e ** mensuração das trocas gasosas. Campina Grande, PB, 2011.

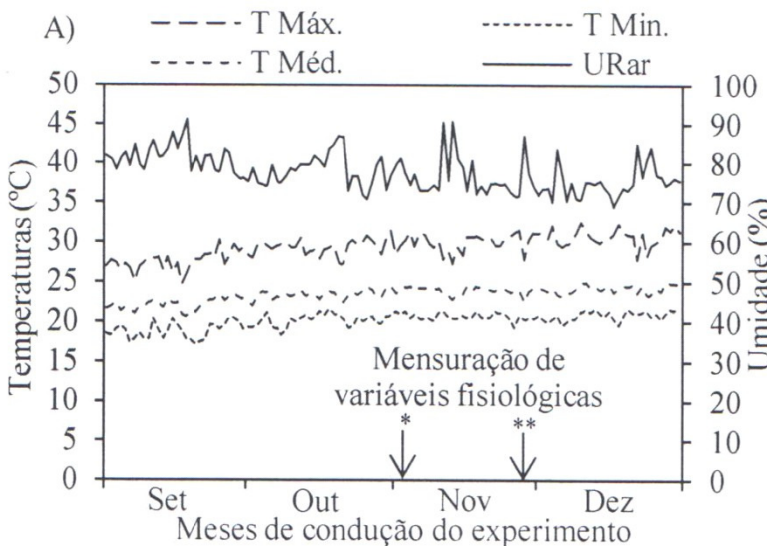

Fonte: Elaboração dos autores.

O solo utilizado no experimento foi classificado como Neossolo Flúvico distrófico (EMBRAPA, 2006). Do mesmo foram coletadas dez amostras simples submetidas ao processo de homogeneização, obtendo-se ao final uma amostra composta. Dessa amostra foram realizadas as análises química e física, cujos resultados foram: $\mathrm{pH}$ em $\mathrm{H}_{2} \mathrm{O}=5,1$; $\mathrm{P}=0,3 \mathrm{mg} \mathrm{dm}^{-3} ; \mathrm{K}=0,5 \mathrm{mmol}_{\mathrm{c}} \mathrm{dm}^{-3} ; \mathrm{Na}=0,4$ $\mathrm{mmol}_{\mathrm{c}} \mathrm{dm}^{-3} ; \mathrm{Ca}=3,7 \mathrm{mmol}_{\mathrm{c}} \mathrm{dm}^{-3} ; \mathrm{Mg}=6,5 \mathrm{mmol}_{\mathrm{c}}$ $\mathrm{dm}^{-3} ; \mathrm{Al}=5,0 \mathrm{mmol}_{\mathrm{c}} \mathrm{dm}^{-3} ; \mathrm{H}+\mathrm{Al}=28,9 \mathrm{mmol}_{\mathrm{c}}$ $\mathrm{dm}^{-3} ; \mathrm{T}=40,0 \mathrm{mmol}_{\mathrm{c}} \mathrm{dm}^{-3} ; \mathrm{V}=28,0 \%$; M.O. $=$ $3,6 \mathrm{~g} \mathrm{~kg}^{-1}$; areia $=81,44 \%$; silte $=13,79 \%$; argila $=$ 4,77\%; densidade do solo $=1,52 \mathrm{~g} \mathrm{~cm}^{-3}$; densidade de partículas $=2,85 \mathrm{~g} \mathrm{~cm}^{-3}$; porosidade $=46,67 \%$; umidade natural $=0,30 \%$; água disponível $=1,43 \%$ e classe textural $=$ franco arenosa.

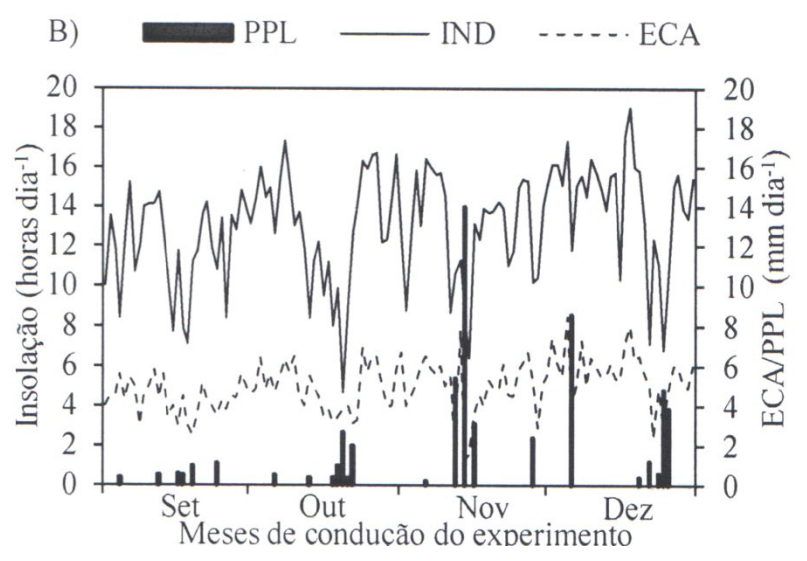

Com base nos resultados da análise, realizou-se a correção da acidez do solo por meio de calagem com calcário dolomítico (PRNT 90\%), cuja quantidade de $1,2 \mathrm{t} \mathrm{ha}^{-1}$ foi calculada com base no alumínio trocável. Após a aplicação do corretivo, antes da semeadura, o mesmo permaneceu incubado durante 60 dias, com homogeneização do material do solo e irrigação semanal, com o objetivo de manter solo em torno de $70 \%$ da capacidade de campo. Conforme sugerido por Oliveira et al. (2008), o solo recebeu, também, adubação corretiva e de manutenção, constituída por NPK, utilizandose fontes comerciais $(\mathrm{N}=$ uréia, $\mathrm{P}=$ superfosfato simples e $\mathrm{K}=$ cloreto de potássio) aplicadas de forma fracionada, 15 dias antes da semeadura foi aplicado a fonte fosfatada, e o restante disponibilizado em 
cobertura obedecendo-se duas aplicações até o florescimento pleno.

As cultivares de fibra colorida utilizadas na pesquisa foram: 'BRS Topázio', 'BRS Safira' e 'BRS Rubi', desenvolvidas pela Embrapa Algodão. Transcorridos 75 dias da correção do solo e 15 dias da adubação do solo, realizou-se a semeadura, adotando-se cinco sementes por unidade experimental, as quais foram tratadas com fungicida e posteriormente semeadas a uma profundidade padrão de $3 \mathrm{~cm}$ da superfície do solo. Aos 15 dias após a emergência (DAE) das plântulas, foi realizado o desbaste por meio da eliminação das plântulas menos vigorosas. Ressalte-se que o cultivo foi realizado em vasos de material orgânico polimérico sintético com capacidade volumétrica de $200 \mathrm{~L}$, os quais foram alocados sobre uma base de alvenaria com dimensões $0,55 \mathrm{~m}$ de altura $\mathrm{x} 0,70$ $\mathrm{m}$ de largura $\mathrm{x}$ 0,70 $\mathrm{m}$ de comprimento. Cada vaso teve sua parte inferior preenchida com $10 \mathrm{~L}$ de brita, formando uma camada de $0,10 \mathrm{~m}$ deste material a qual constituiu um dreno, sendo o restante do volume do vaso preenchido com solo. Deve-se salientar que a equidistância entre os vasos foi de $1,5 \mathrm{~m}$.

Acrescente-se que as irrigações foram realizadas elevando-se, no inicio, a umidade do solo em torno de $70 \%$ da capacidade de campo (CC). A reposição da água evapotranspirada pelas plantas (ETc) ocorreu em função da evaporação do tanque classe 'A' (ECA) e do coeficiente da culturas (Kc) nas diferentes fases fenológicas das plantas (BEZERRA et al., 2012).

O delineamento experimental utilizado foi o inteiramente casualizado (DIC), montado em esquema fatorial $3 \times 5$, sendo três cultivares de algodoeiro herbáceo: $\left(\mathrm{CV}_{1}=\right.$ 'BRS Topázio', $\mathrm{CV}_{2}=$ 'BRS Safira' e $\mathrm{CV}_{3}=$ 'BRS Rubi'), cinco doses de silício $\left(0,50,100,150,200 \mathrm{mg} \mathrm{L}^{-1}\right)$, via foliar e quatro repetições. As concentrações foram obtidas por meio de diluição de silicato de potássio $\left(\operatorname{Sifol}^{\circledR}\right)$ em água destilada. A unidade experimental foi constituída por um vaso (200 L) contendo uma planta útil, totalizando 60 parcelas experimentais.

Transcorridos 15 dias após a emergência das plântulas, considerando-se esse período suficiente para estabelecimento das plantas no ambiente de cultivo, realizaram-se, semanalmente, as aplicações de silício via foliar. As pulverizações foram direcionadas às faces abaxiais e adaxiais das folhas do algodoeiro, até o ponto de escorrimento da solução silicatada. De modo evitar possível contato da mesma com o solo, a superfície dos vasos era coberta com lona plástica. Para melhor eficiência no uso do silício na superfície foliar, utilizou-se surfactante na solução de pulverização (SÁVIO et al., 2011). Na pulverização foliar, utilizou-se pulverizador manual de compressão prévia com tanque em polietileno de alta massa molar, com capacidade volumétrica de $5 \mathrm{~L}$ e bomba tipo pistão com diâmetro do bico de $34 \mathrm{~mm}$.

As avaliações das trocas gasosas foram realizadas aos 90 dias após a semeadura (DAS) a partir da mensuração da taxa de assimilação de $\mathrm{CO}_{2}(A)\left(\mu \mathrm{mol} \mathrm{m} \mathrm{m}^{-2} \mathrm{~s}^{-1}\right)$, transpiração $(E)$ (mmol de $\mathrm{H}_{2} \mathrm{Om}^{-2} \mathrm{~s}^{-1}$ ), condutância estomática (gs mol $\left.\mathrm{m}^{-2} \mathrm{~s}^{-1}\right)$ e concentração interna de $\mathrm{CO}_{2}(\mathrm{Ci})(\mu \mathrm{mol}$ mol $^{-1}$ ) (AMARAL; RENA; AMARAL, 2006). De posse desses dados, foram estimadas a eficiência instantânea no uso da água (EiUA) $(A / E)\left[\left(\mu \mathrm{mol} \mathrm{m} \mathrm{m}^{-2}\right.\right.$ $\left.\left.\mathrm{s}^{-1}\right)\left(\mathrm{mmol} \mathrm{H}_{2} \mathrm{O} \mathrm{m}^{-2} \mathrm{~s}^{-1}\right)^{-1}\right]$ e a eficiência instantânea da carboxilação (EiC) (A/Ci) $\left[\left(\mu \mathrm{mol} \mathrm{m}{ }^{-2} \mathrm{~s}^{-1}\right)(\mu \mathrm{mol}\right.$ $\left.\mathrm{mol}^{-1}\right)^{-1}$, de acordo com a metodologia descrita em Amaral, Rena e Amaral (2006) e Carneiro (2011). Para as avaliações utilizou-se um analisador de gás infravermelho (IRGA) modelo LCpro+Sistem. Determinou-se também a fluorescência da clorofila 'a', no turno da manhã (8-9h) no período de floração plena (60 DAS) do algodoeiro, utilizandose de um fluorômetro portátil (LI-1600, USA). As leituras de trocas gasosas e de fluorescência da clorofila ' $a$ ' foram realizadas na primeira folha totalmente expandida contada a partir da base do primeiro ramo com botão floral. Para mensuração das variáveis de fluorescência as folhas foram pré- 
adaptadas ao escuro por 30 minutos registrandose as fluorescências: inicial (Fo), máxima (Fm), variável (Fv) e eficiência quântica do FSII (Fv/Fm) (SUASSUNA et al., 2011).

Os dados das variáveis respostas foram submetidos à análise de variância pelo teste $\mathrm{F}$, até $5 \%$ de probabilidade de erro. Para o fator quantitativo, a escolha do modelo de regressão, para cada variável, baseou-se na significância do coeficiente de regressão (teste t-Student) e a proporção da variância explicada pelas equações dos modelos foi dada pelo coeficiente de determinação $\left(\mathrm{R}^{2}\right)$. Quanto ao fator qualitativo, foi aplicado o teste de comparação de médias (teste de Tukey) (SANTOS et al., 2008). Para as análises estatísticas dos resultados, foram utilizados os softwares SAEG 9.1 e Table Curve 2D.

\section{Resultados e Discussão}

Com base nos resultados obtidos, verificase que houve diferenças significativas, aos 90 dias após a semeadura (DAS), em resposta às aplicações de diferentes concentrações de silício via foliar sobre as variáveis: taxa de assimilação de $\mathrm{CO}_{2}(A)$, condutância estomática $(\mathrm{gs})(\mathrm{p}<0,05)$, concentração interna de $\mathrm{CO}_{2}(\mathrm{Ci})$ e, aos 60 DAS sobre a fluorescência máxima (Fm), fluorescência variável (Fv) e eficiência quântica do fotossistema II $(\mathrm{Fv} / \mathrm{Fm})(\mathrm{p}<0,01)$. Também foram constatadas diferenças significativas entre as cultivares avaliadas para as variáveis: taxa de assimilação de $\mathrm{CO}_{2}(A)$ $(\mathrm{p}<0,01)$, condutância estomática $(\mathrm{gs})(\mathrm{p}<0,05)$, concentração interna de $\mathrm{CO}_{2}(\mathrm{Ci})$, fluorescência máxima $(\mathrm{Fm})$ e fluorescência variável $(\mathrm{p}<0,01)$ (Tabela 1).

A taxa de assimilação de $\mathrm{CO}_{2}(A)$, na cultivar 'BRS Topázio', aos 90 DAS, teve ajuste polinomial quadrático, sendo o maior valor de $A(11,3 \mu \mathrm{mol}$ $\mathrm{m}^{-2} \mathrm{~s}^{-1}$ ) estimado com a aplicação de $111,4 \mathrm{mg}$ $\mathrm{L}^{-1}$ de silício. Registrou-se aumento de 27,8\% na assimilação de dióxido de carbono com o aumento da concentração de silício aplicada até o nível de 111,4 $\mathrm{mg} \mathrm{L}^{-1}$ com relação às plantas cultivadas na ausência do elemento (0 $\left.\mathrm{mg} \mathrm{L}^{-1}\right)$ (Figura 2A). A cultivar 'BRS Safira' expressou redução linear acentuada de 49\% na assimilação de dióxido de carbono em resposta ao incremento nas concentrações de silício, sendo estimada maior assimilação desse gás (14,9 $\mu \mathrm{mol} \mathrm{m} \mathrm{m}^{-2} \mathrm{~s}^{-1}$ ) nas plantas cultivadas sem aplicação de silício, contrastando-se com o valor crítico de 7,6 $\mu \mathrm{mol} \mathrm{m} \mathrm{m}^{-2} \mathrm{~s}^{-1}$ estimado com a aplicação da dose de $200 \mathrm{mg} \mathrm{L}^{-1} \mathrm{Si}$ (Figura 2B). Observou-se, na cultivar 'BRS Rubi', redução de 32\% na taxa de assimilação de $\mathrm{CO}_{2}$ no intervalo entre as doses de 0 a $134 \mathrm{mg}$ $\mathrm{L}^{-1}$, com ajuste ao modelo polinomial quadrático. A partir do valor crítico $\left(7,3 \mu \mathrm{mol} \mathrm{m} \mathrm{m}^{-2} \mathrm{~s}^{-1}\right)$ estimado na concentração de Si de $134 \mathrm{mg} \mathrm{L}^{-1}$, observou-se tendência de aumento em $7,4 \%$ na $A$ até a dose de $200 \mathrm{mg} \mathrm{L}^{-1}$, onde foi encontrado maior valor $(7,9$ $\left.\mu \mathrm{mol} \mathrm{m} \mathrm{m}^{-2} \mathrm{~s}^{-1}\right)$ de assimilação de $\mathrm{CO}_{2}$ com relação ao ponto crítico (Figura 2C). Houve interação significativa entre os fatores estudados com valor de $15,1 \mu \mathrm{mol} \mathrm{m} \mathrm{m}^{-2} \mathrm{~s}^{-1}$ observado nas plantas de 'BRS Topázio’ cultivadas sem aplicação de silício (Figura 2D).

As taxas de assimilação de $\mathrm{CO}_{2}$ foram inferiores aos valores informados por Ferreira (2008) trabalhando com algodoeiro 'BRS Cedro' sob diferentes doses de silício em solução nutritiva, o que se justifica pela forma de aplicação via hidroponia utilizada por esse autor, notadamente, pela maior facilidade de absorção do elemento nesse meio. O comportamento quadrático da 'BRS Topázio' foi semelhante ao da 'BRS Cedro' cientificado por Ferreira (2008), quando cultivada em solução nutritiva contendo silício na dose de 50 $\mathrm{mg} \mathrm{L} \mathrm{L}^{-1}$. Por outro lado, as cultivares 'BRS Safira' e 'BRS Rubi' tiveram tendência divergente do que preconizou esse autor, notadamente pela redução da taxa de assimilação de $\mathrm{CO}_{2}$; o que não condiz com Korndorfer e Oliveira (2010), quando ressaltam que o silício aumenta a capacidade fotossintética em plantas herbáceas. 
Tabela 1. Resumo das análises de variância para as variáveis: taxa de assimilação de $\mathrm{CO}_{2}(A)\left(\mu \mathrm{mol} \mathrm{m} \mathrm{m}^{-2} \mathrm{~s}^{-1}\right)$, transpiração $(E)\left(\mathrm{mmol}\right.$ de $\left.\mathrm{H}_{2} \mathrm{O} \mathrm{m} \mathrm{m}^{-2} \mathrm{~s}^{-1}\right)$, condutância estomática $\left(\mathrm{gs} \mathrm{mol} \mathrm{m} \mathrm{m}^{-2} \mathrm{~s}^{-1}\right)$, concentração interna de $\mathrm{CO}_{2}(\mathrm{Ci})$ ( $\left.\mu \mathrm{mol} \mathrm{mol}^{-1}\right)$, eficiência instantânea no uso da água (EiUA) $\left[\left(\mu \mathrm{mol} \mathrm{m} \mathrm{s}^{-1}\right)\left(\mathrm{mmol} \mathrm{H}_{2} \mathrm{O} \mathrm{m}^{-2} \mathrm{~s}^{-1}\right)^{-1}\right]$, eficiência instantânea da carboxilação (EiC) $(\mathrm{A} / \mathrm{Ci})\left[\left(\mu \mathrm{mol} \mathrm{m} \mathrm{s}^{-1}\right)\left(\mu \mathrm{mol} \mathrm{mol}{ }^{-1}\right)^{-1}\right]$, fluorescência inicial (Fo), fluorescência máxima $(\mathrm{Fm})$, fluorescência variável (Fv) e eficiência quântica do fotossistema II ( $\mathrm{Fv} / \mathrm{Fm})$ em cultivares de algodoeiro sob aplicação de silício foliar. Campina Grande, PB, 2012.

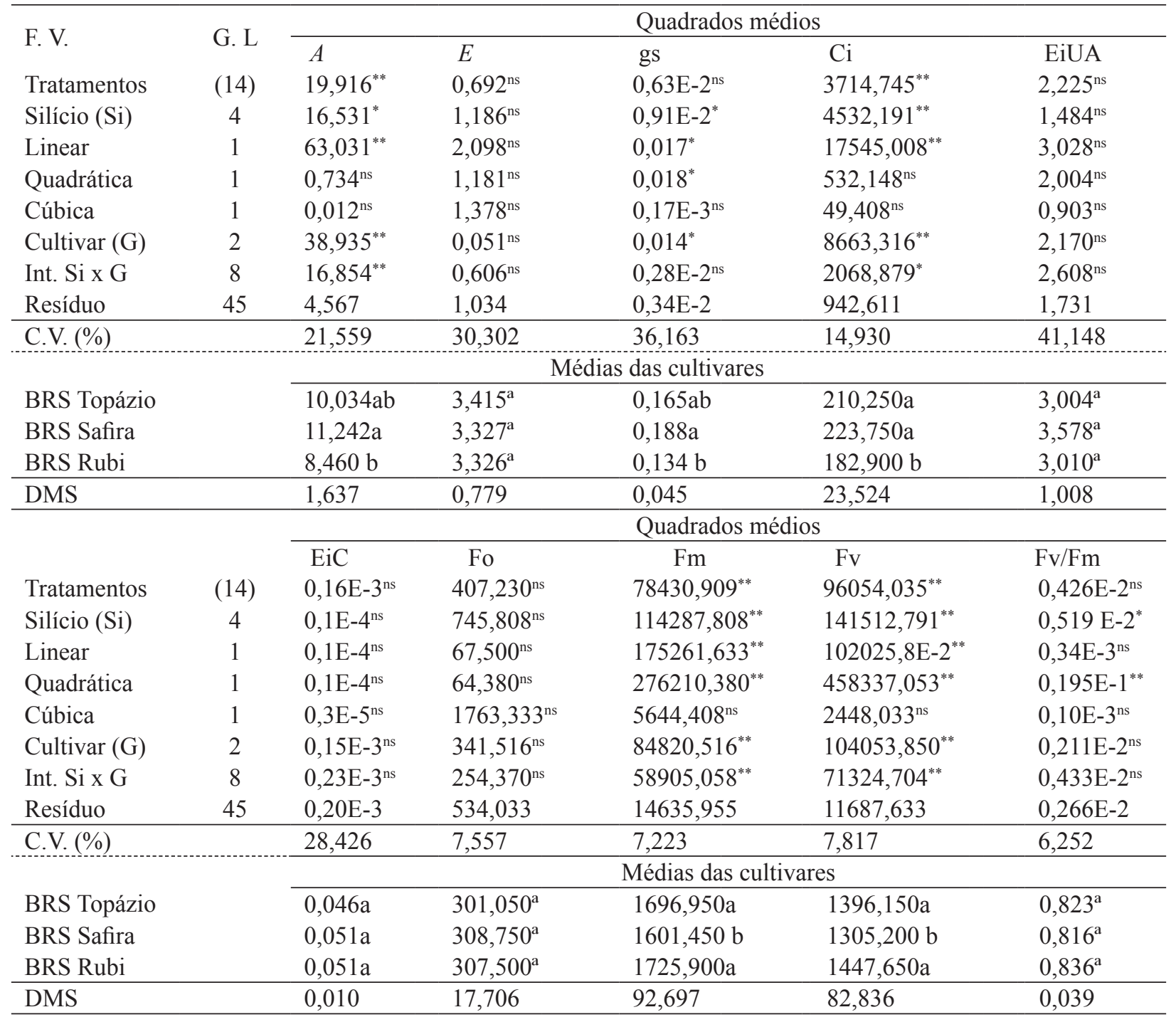

F.V. - Fontes de variação; C.V. - Coeficiente de variação; G.L. - Graus de liberdade; Int. - Interação; **, * - Significativo a 1 e $5 \%$ respectivamente; ns - Não significativo pelo teste F a 5\% de probabilidade.

Fonte: Elaboração dos autores. 
Figura 2. Taxa de assimilação de $\mathrm{CO}_{2}(A)$ das cultivares de algodoeiro 'BRS Topázio' (A), 'BRS Safira' (B) e 'BRS Rubi' (C) em cultivo sob aplicação de silício via foliar e interação silício (Si) x cultivares (G) (D). Campina Grande, $\mathrm{PB}, 2012$.
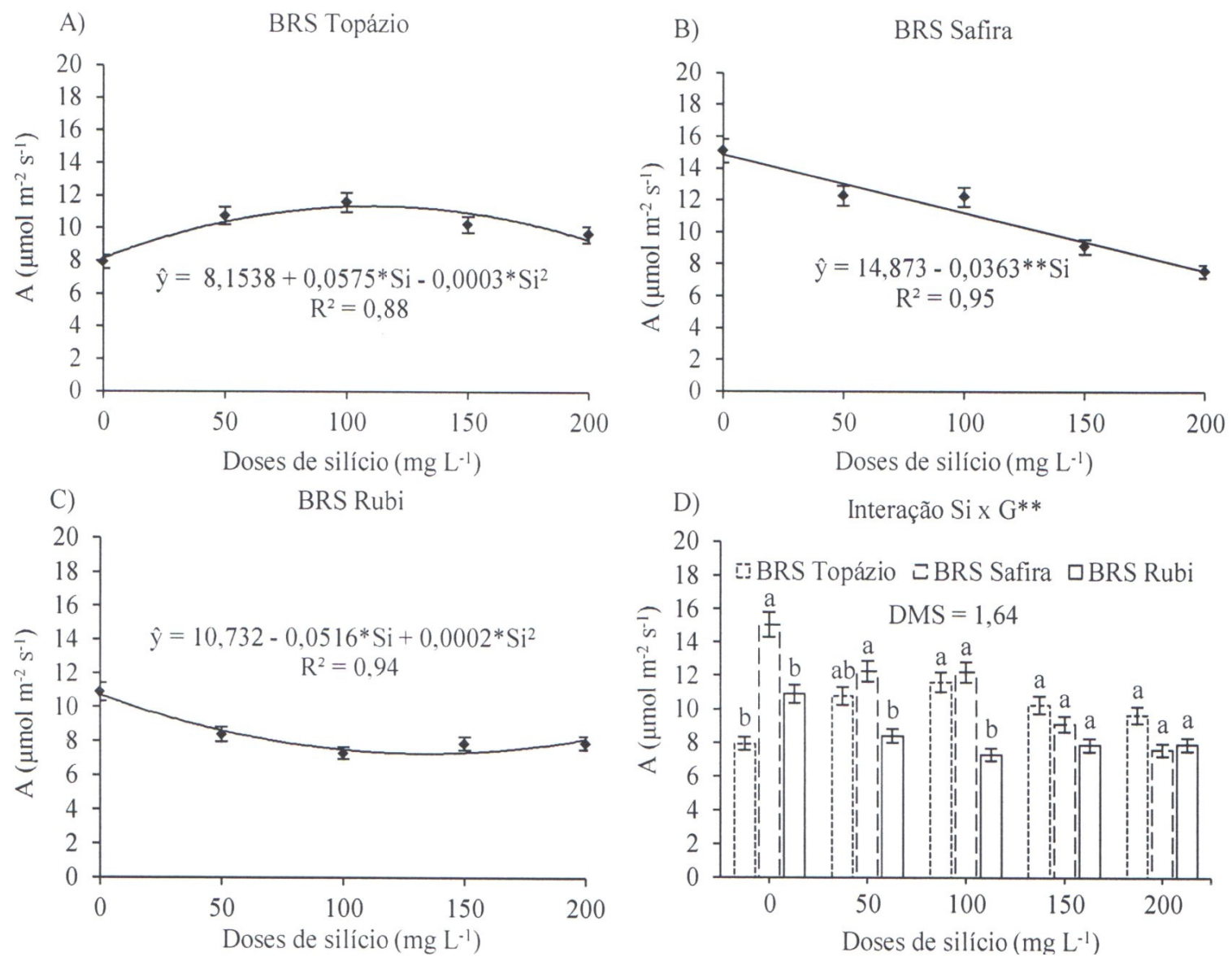

Fonte: Elaboração dos autores.

Transcorridos 90 dias após a semeadura (DAS), observou-se reduções de 35,9e 49,7\% na condutância estomática (gs), com valores críticos de 0,13 e 0,10 mol m $\mathrm{m}^{-2} \mathrm{~s}^{-1}$ estimados com a aplicação de 103,4 e 115,3 mg L'-1 de Si nas cultivares 'BRS Topázio' e 'BRS Rubi', respectivamente. Essas reduções na gs foram estimadas em relação aos maiores valores de condutância 0,20 e $0,18 \mathrm{~mol} \mathrm{~m}^{-2} \mathrm{~s}^{-1}$ obtidos nas plantas que não foram submetidas à aplicação de $\mathrm{Si}$ $\left(0 \mathrm{mg} \mathrm{L}^{-1}\right)$ para as respectivas cultivares. A partir dos pontos de menor gs obtidos nas curvas de ajuste das médias de 'BRS Topázio' e 'BRS Rubi', verificouse que o incremento da concentração de Si nas soluções de pulverização promoveu aumentos de 35,9 e 28,6\% na condutância estomática em relação aos valores $\left(0,20 \mathrm{mmol} \mathrm{m}^{-2} \mathrm{~s}^{-1}\right)$ e $\left(0,14 \mathrm{mmol} \mathrm{m}^{-2}\right.$ $\left.\mathrm{s}^{-1}\right)$ obtidos na concentração de $200 \mathrm{mg} \mathrm{L}^{-1}$ de silício (Figura 3A e B).

O monitoramento da dinâmica estomática é de fundamental importância para o entendimento dos processos fisiológicos, em virtude dos estômatos constituírem a principal via de trocas gasosas entre a atmosfera e o interior do aparato fotossintético (AMARAL; RENA; AMARAL, 2006). O comportamento quadrático das cultivares de algodoeiro 'BRS Topázio' e 'BRS Rubi’ constatado nessa pesquisa corrobora com o ajuste das médias da 'BRS Cedro' verificado por Ferreira (2008). Esse pesquisador salienta que, a redução da condutância 
estomática reflete em menor transpiração e, consequentemente, menor perda de água pelas plantas, conferindo ao vegetal maior resistência aos estresses abióticos. É importante ressaltar que os dados de condutância estomática obtidos nesta pesquisa e os informados por Ferreira (2008) encontram-se fora da faixa de oscilação entre 300 e
$500 \mathrm{mmol}$ de $\mathrm{H}_{2} \mathrm{O} \mathrm{m}^{-2} \mathrm{~s}^{-1}$, que comumente ocorre na maioria das plantas herbáceas (LARCHER, 2006). De acordo com Paiva et al. (2005), a condutância estomática regula as trocas gasosas e, portanto, possui relação direta com o processo fotossintético e consequente crescimento e desenvolvimento dos vegetais.

Figura 3. Condutância estomática (gs) das cultivares de algodoeiro 'BRS Topázio' (A) e 'BRS Rubi' (B) em cultivo sob aplicação de silício via foliar. Campina Grande, PB, 2012.

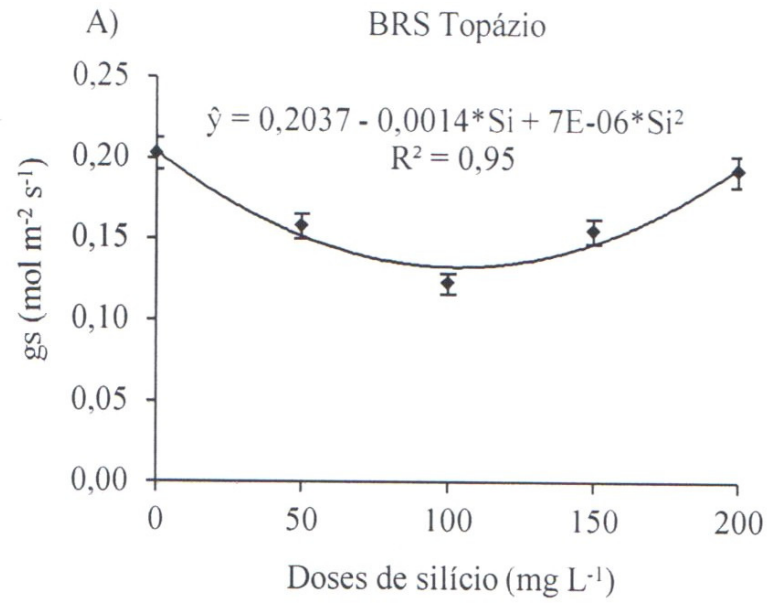

Fonte: Elaboração dos autores.

O aumento da concentração de silício nas soluções aplicadas via foliar promoveu redução acentuada na concentração interna de $\mathrm{CO}_{2}(\mathrm{Ci})$ nas cultivares 'BRS Safira' e 'BRS Rubi'. As taxas de deflexão estimadas para as duas cultivares foram de 30,4 e $32,7 \%$, verificadas na oscilação de 0 a 200 $\mathrm{mg} \mathrm{\textrm {L } ^ { - 1 }}$ de silício, com valores mais expressivos $\left(263,9 \mu \mathrm{mol} \mathrm{mol}^{-1}\right)$ e $\left(218,6 \mu \mathrm{mol} \mathrm{mol}^{-1}\right)$ revelados nas plantas que não foram tratadas com silício foliar, contrastando-se com os valores críticos $\left(183,6 \mu \mathrm{mol} \mathrm{mol}^{-1}\right)$ e $\left(147,2 \mu \mathrm{mol} \mathrm{mol}{ }^{-1}\right)$ estimados nas plantas submetidas a aplicação foliar de 200 $\mathrm{mg} \mathrm{L}^{-1}$ de silício (Figura 4A e B). Constatou-se interação significativa entre silício e cultivares para a variável concentração interna de $\mathrm{CO}_{2}$, sendo maior valor de $\mathrm{Ci}\left(264 \mu \mathrm{mol} \mathrm{mol}{ }^{-1}\right)$ verificado nas plantas cultivadas sem aplicação do elemento na cultivar 'BRS Safira' (Figura 4C).

As reduções registradas na concentração interna

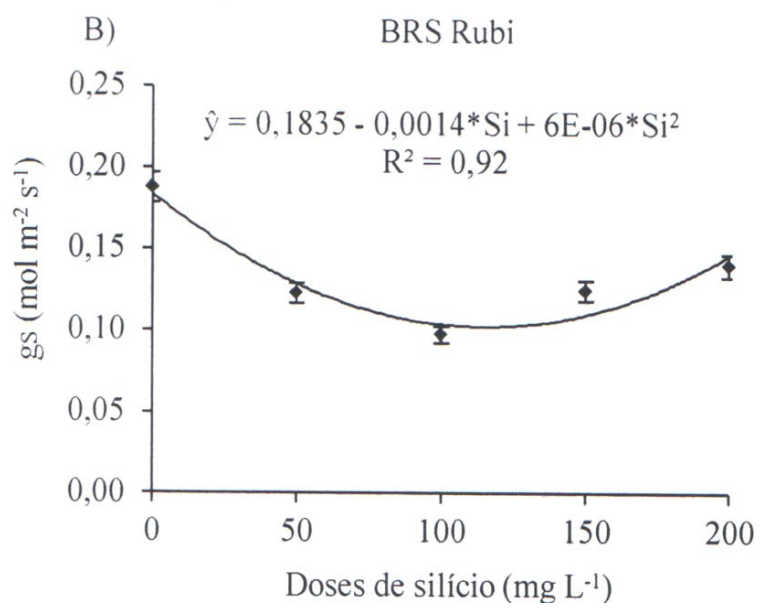

de $\mathrm{CO}_{2}$ refletem as diminuições constatadas na taxa de assimilação de dióxido de carbono, o que se justifica pelo fato que durante o processo de trocas gasosas, a absorção de $\mathrm{CO}_{2}$ converge na perda de água e, em sentido contrário, a redução dessa perda restringe a assimilação de dióxido de carbono e, consequentemente, acarreta menor concentração interna de $\mathrm{CO}_{2}$ (SHIMAZAKI et al., 2007). Variações significativas nas trocas gasosas dos vegetais são fortemente influenciadas pelas condições climáticas proeminentes dos diversos ecossistemas, não obstante, o suprimento nutricional possui estreita relação com variações nas trocas gasosas (TAIZ; ZEIGER, 2013). Essas assertivas, associadas às características genéticas das cultivares, ratificam a ocorrência de diferenças significativas entre as concentrações de carbono interno nas cultivares de algodoeiro, notadamente, pela constatação de interação entre os fatores cultivar e silício. 
Figura 4. Concentração interna de $\mathrm{CO}_{2}(\mathrm{Ci})$ das cultivares de algodoeiro 'BRS Safira' (A) e 'BRS Rubi' (B) e interação silício (Si) x cultivar (G) (C) em cultivo sob aplicação de silício via foliar. Campina Grande, PB, 2012.
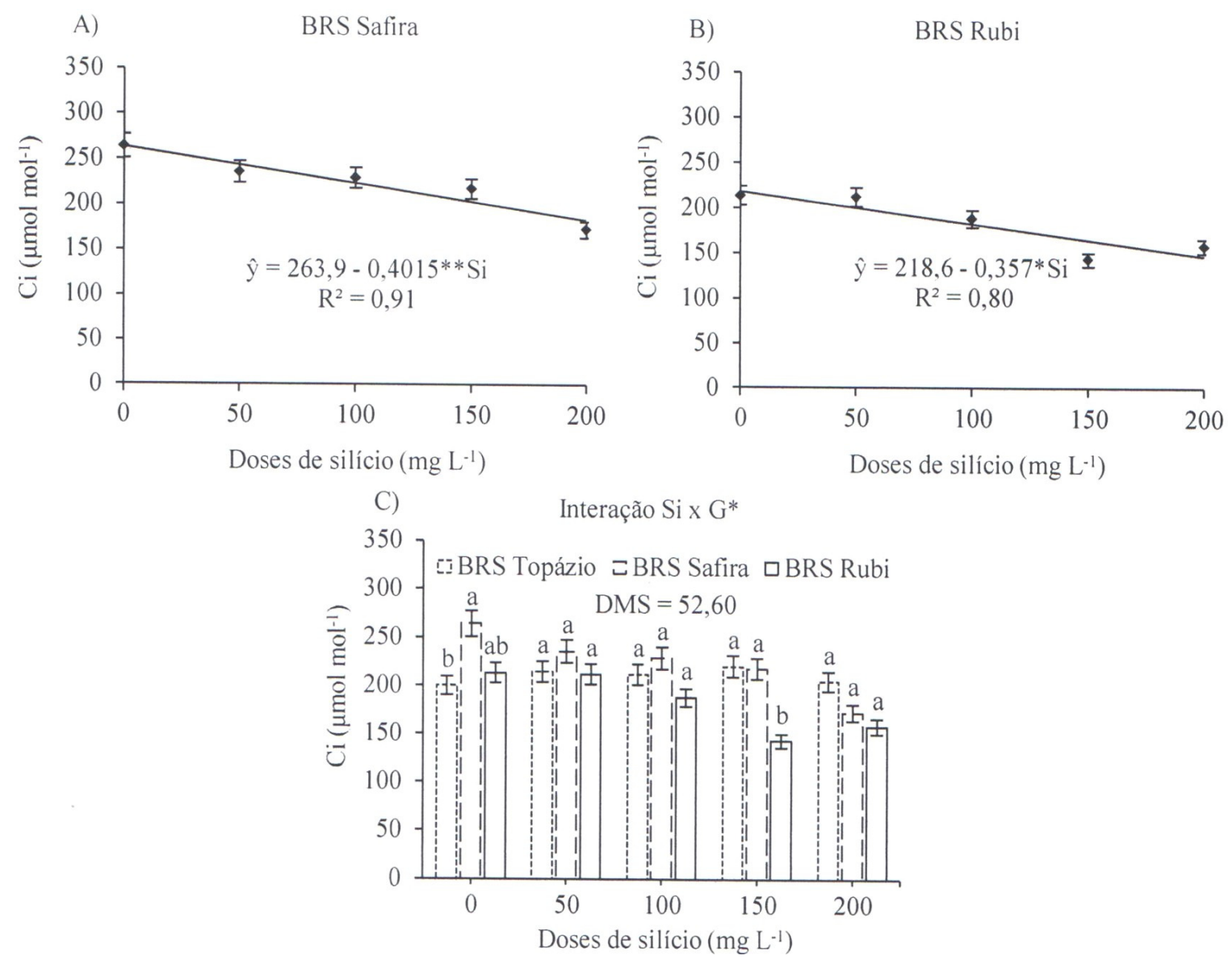

Fonte: Elaboração dos autores.

Verificou-se que a cultivar 'BRS Topázio' teve maior fluorescência máxima (Fm) $(1824,6)$ com a aplicação da concentração de silício de $125,4 \mathrm{mg}$ $\mathrm{L}^{-1}$, constatando-se incremento de $19,5 \%$ em relação à média de 1468,9 obtida nas plantas que não foram tratados com silício foliar (0 $\left.\mathrm{mg} \mathrm{L}^{-1}\right)$ (Figura $\left.5 \mathrm{~A}\right)$. A cultivar 'BRS Rubi' expressou comportamento semelhante ao da 'BRS Topázio', observando-se que, na oscilação de 0 a $111,8 \mathrm{mg} \mathrm{L}^{-1}$ de silício, foi estimado aumento de $25,1 \%$ na fluorescência máxima de 'BRS Rubi', sendo este ganho estimado a partir dos valores mínimo $(1424,1)$ e máximo $(1901,5)$ para as respectivas concentrações desse micronutriente. Por outro lado, a partir do valor máximo estimado, verifica-se redução de $14 \%$ até o nível máximo (200 $\mathrm{mg} \mathrm{L}^{-1}$ ) de silício testado, o qual revelou o valor de 1634,6 em Fm (Figura 5B). Registrou-se interação significativa entre os fatores estudados sobre a variável Fm, com valor mais expressivo $(1879,5)$ verificado na interação entre a cultivar 'BRS Topázio' e a concentração de $100 \mathrm{mg}$ $\mathrm{L}^{-1}$ de silício (Figura $5 \mathrm{E}$ ). 
Figura 5. Fluorescência máxima (Fm) e fluorescência variável (Fv) da clorofila 'a' das cultivares de algodoeiro 'BRS Topázio' (A) e (C) e 'BRS Rubi' (B) e (D) e interação silício (Si) x cultivar (G) (E) e (F) em cultivo sob aplicação de silício via foliar. Campina Grande, PB, 2012.
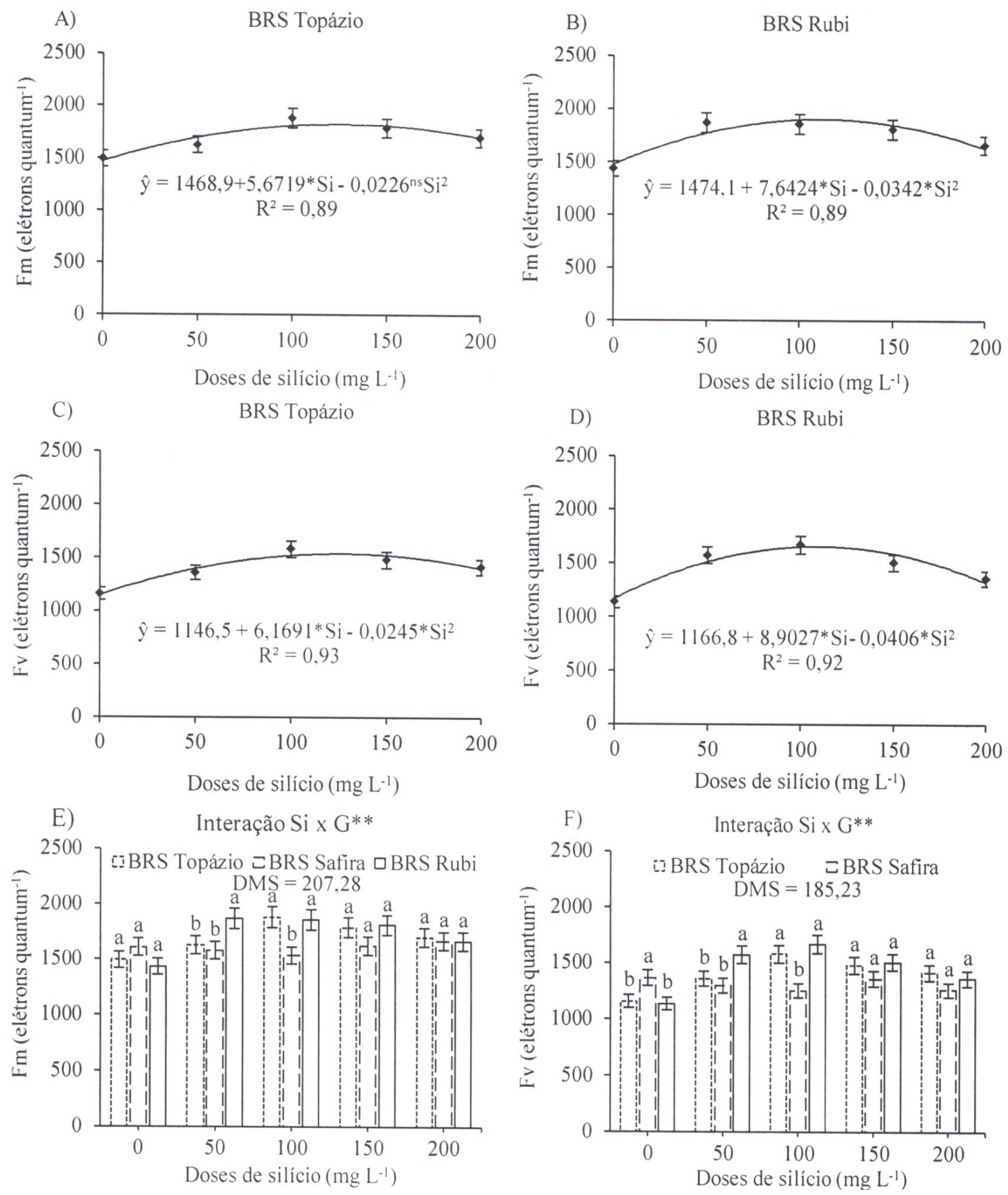

Fonte: Elaboração dos autores. 
A fluorescência da clorofila 'a', em nível majoritário, é emitida pelo fotossistema II (FSII) e pelo sistema coletor de luz do FSII (LightHarvesting Complex II - LHCII). Ressalte-se que, o fotossistema I (FSI) também contribui na emissão da fluorescência, notadamente, na região de comprimentos de ondas maiores. É conveniente frisar que a emissão de fluorescência proveniente do FSI contribuir para a fluorescência inicial(KRAUSE; WEIS, 1988). Acrescente-se que a competitividade entre os processos de dissipação de energia luminosa da clorofila provoca alterações na exaustão de calor e emissão de fluorescência, podendo, sobretudo, comprometer o processo fotossintético. Esse aumento verificado na Fm das cultivares 'BRS Topázio' e ‘BRS Rubi' justifica-se pela otimização da capacidade de absorção e aproveitamento da energia luminosa pelo fotossistema II (TORRES NETTO; CAMPOSTRINI; OLIVEIRA, 2005). Acrescentese que o aumento da fluorescência máxima está relacionado à maior eficiência de fotorredução da quinona $a$ indicando boa atividade do FSII na membrana dos tilacóides, o que reflete diretamente no fluxo de elétrons entre os fotossistemas (SILVA et al., 2006).

A fluorescência variável ( $\mathrm{Fv})$, na cultivar 'BRS Topázio’, teve emissão mais expressiva $(1535,1)$ com a aplicação de $126 \mathrm{mg} \mathrm{L}^{-1}$ de Si. Comparandose o valor médio $(1146,5)$ obtido nas plantas que não foram tratadas com silício e os valores mais expressivos obtidos para esta variável, é possível estimar taxa de incremento de 25,3\% em Fv (Figura 5C). Para a 'BRS Rubi', também pôde-se verificar aumento da ordem de 29,5\% na fluorescência variável, sendo esse aumento estimado a partir do menor valor $(1166,8)$ e o maior valor $(1654,5)$ de Fv, obtidos na oscilação de 0 a $109,6 \mathrm{mg} \mathrm{L}^{-1}$ de silício aplicado (Figura 5D). Verificou-se interação significativa entre cultivares e silício com maior valor de Fv $(1667,2)$ registrado na cultivar 'BRS Rubi' quando submetida à aplicação de $100 \mathrm{mg} \mathrm{L}^{-1}$ de silício (Figura 5F).
Dias e Marenco (2007) reportam que as características de fluorescência são utilizadas como indicativo de estresses bióticos e abióticos, notadamente, pelo dano causado por esses fatores ao pleno funcionamento do FSII. Assim, o aumento verificado na fluorescência variável, em resposta ao incremento da concentração de silício aplicado, indica maior estabilidade das plantas e consequente proteção a possíveis estresses. Essa informação é ratificada por Crusciol e Soratto (2010), os quais destacam que o efeito do Si inibe a severidade dos estresses e potencializa as atividades metabólicas e consequentemente fisiológicas dos vegetais. Suassuna et al. (2011) acrescentam que variáveis de fluorescência são determinadas por métodos não-destrutivos, o que indica maior comodidade e flexibilidade para os pesquisadores.

A 'BRS Rubi' expressou maior eficiência quântica do fotossistema II $(0,87)$ com a aplicação de 104,7 $\mathrm{mg} \mathrm{L}^{-1}$ de silício, evidenciando aumento de $9,2 \%$ na eficiência fotoquímica quando os valores $(0,79)$ obtidos nas plantas não tratadas com silício (0 $\left.\mathrm{mg} \mathrm{L}^{-1}\right)$ foram comparados aos estimados no ponto máximo da curva (Figura 6).

Deve-se ressaltar que os valores de eficiência quântica do fotossistema II evidenciados nesta pesquisa corroboram aos preconizados por Bjorkman (1987). Esse pesquisador reportou que em plantas vasculares sadias a relação Fv/Fm deve compreender valores entre $0,832 \pm 0,004$.

A eficiência quântica do FSII pode ser utilizada para indicar estresse nos vegetais. Nesse sentido, a diminuição da relação $\mathrm{Fv} / \mathrm{Fm}$ indica distúrbios na eficiência fotoquímica. Essa informação é ratificada por Melo et al. (2010) e Suassuna et al. (2011) quando os autores registraram redução na Fv/Fm em melancieira e meloeiro, respectivamente, submetidos à condição de estresse por saturação hídrica. Posada, Olmos e Ulrichs (2011) ressaltam que a relação $\mathrm{Fm} / \mathrm{Fv}$ caracteriza a eficiência fotoquímica das culturas e indica pleno funcionamento do aparato fotossintético das 
plantas. Assim, o aumento da eficiência quântica do FSII indica melhor aproveitamento e conversão da energia luminosa. A maior eficiência quântica do FSII observada na 'BRS Rubi' pode estar atrelada ao incremento da dose de silício nas soluções de pulverização, notadamente, pelos diversos efeitos benéficos (MADEIROS; VIEIRA; AQUINO, 2009).

Figura 6. Eficiências quântica do fotossistema II (Fm/Fv) da cultivar de algodoeiro 'BRS Rubi' em cultivo sob aplicação de silício via foliar. Campina Grande, PB, 2012.

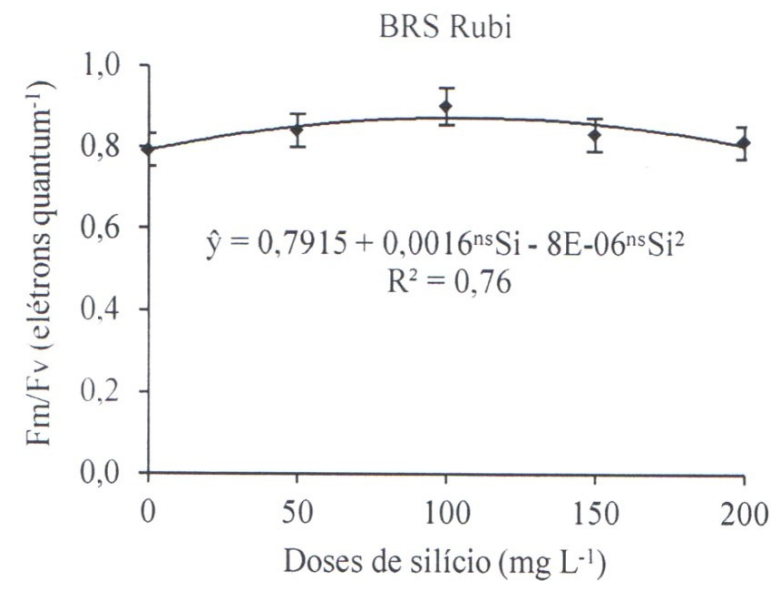

Fonte: Elaboração dos autores.

\section{Conclusão}

$\mathrm{Na}$ 'BRS Topázio', a aplicação de silício aumentou a taxa de assimilação de $\mathrm{CO}_{2}$ e eficiência quântica do fotossistema II. Na 'BRS Safira' o silício reduziu a taxa de assimilação e concentração interna de $\mathrm{CO}_{2}$. Na 'BRS Rubi' o elemento aumentou a fluorescência da clorofila ' $a$ ' e eficiência quântica do fotossistema II e, reduziu a taxa de assimilação e concentração interna de $\mathrm{CO}_{2}$ e condutância estomática. A adubação silicatada propiciou à cultivar 'BRS Topázio' expressar melhor taxa fotossintética em relação às 'BRS Safira' e 'BRS Rubi. Não ocorreu dano no FSII quando as cultivares 'BRS Topazio', 'BRS Safira' e 'BRS Rubi”' receberam nutrição suplementar de silício.

\section{Agradecimentos}

Ao Programa de Pós-Graduação em Ciências Agrárias da Universidade Estadual da Paraíba
- UEPB, ao Centro Nacional de Pesquisa de Algodão CNPA/Embrapa e à Coordenação de Aperfeiçoamento de Pessoal de Nível Superior CAPES.

\section{Referências}

AMARAL, J. A. T. do; RENA, A. B.; AMARAL, J. F. $\mathrm{T}$ do. Crescimento vegetativo sazonal do cafeeiro e suas relações com fotoperíodo, frutificação, resistência estomática e fotossíntese. Pesquisa Agropecuária Brasileira, Brasília, v. 41, n. 3, p. 377-384, 2006.

ANUÁRIO BRASILEIRO DO ALGODÃO - ABA. Algodão. Santa Cruz do Sul: Editora Gazeta Santa Cruz, 2012.

BEZERRA, M. V. C.; SILVA, B. B. da; BEZERRA, B. G.; BORGES, V. P.; OLIVEIRA, A. S. de. Evapotranspiração e coeficiente de cultura do algodoeiro irrigado a partir de imagens de sensores orbitais. Revista Ciência Agronômica, Fortaleza, v. 43, n. 1, p. 64-71, 2012.

BJORKMAN, O. Fluorescence in leaves and its relationship to photon yield of photosynthesis in photoinhibition. In: KYLE, D. J.; OSMOND, C. B.; 
ARNTZEN, C. J. Photoinhibition. Amsterdam: Elsevier Publisher, 1987.

CARNEIRO, M. M. L. C. Trocas gasosas e metabolismo antioxidativo em plantas de girassol em resposta ao déficit hídrico. 2011. Dissertação (Mestrado em Fisiologia Vegetal) - Programa de Pós-Graduação em Fisiologia Vegetal. Universidade Federal de Pelotas, Pelotas.

COMPANHIA NACIONAL DE ABASTECIMENTO - CONAB. Acompanhamento da safra brasileira: algodão. Décimo levantamento. Brasília: Conab, 2012. Disponível em: <http://www.coanb.gov.br/OlalaCMA/ uploads/arquivos/12_07_1-_08_42_35_algodao02a0607 2012.pdf $>$. Acesso em: jun. 2012.

CRUSCIOL, C. A. C.; SORATTO, R. P. Importância do silício na tolerância das plantas a estresses de natureza abiótica In: RODRIGUES, F, de A. Silício na agricultura. 5. ed. Viçosa, 2010. cap. 2, p. 27-45.

DEEBA, F.; PANDEY, A. K.; RANJAN, S.; MISHRA, A.; SINGH, R.; SHARMA, Y. K.; SHIRKE, P. A.; PANDEY, V. Physiological and proteomic responses of cotton (Gossypium herbaceum L.) to drought stress. Plant Physiology and Biochemistry, Paris, v. 53, n. 4, p. 6-18, 2012.

DIAS, D. P.; MARENCO, R.A. Fotossíntese e fotoinibição em mogno e acariquara em função da luminosidade e temperatura foliar. Pesquisa Agropecuária Brasileira, Brasília, v. 42, n. 3, p. 305-311, 2007.

EMPRESA BRASILEIRA DE PESQUISA AGROPECUÁRIA - EMBRAPA. Centro Nacional de Pesquisa de Solos. Sistema brasileiro de classificação de solos. 2. ed. Rio de Janeiro: Embrapa Solos, 2006. 306 p.

FERREIRA, S. M. Efeito do silício na cultura do algodoeiro (Gossipium hirsutum L.): aspectos bioquímicos, qualidade de fibra e produtividade. 2008. Tese (Doutorado em Ecologia Aplicada) - Escola Superior de Agricultura Luiz de Queiroz. Universidade de São Paulo, Piracicaba.

GUERRERO, A. C.; BORGES, L. da S.; FERNANDES, D. M. Efeito da aplicação foliar de silício em rúcula cultivada em dois tipos de solos. Bioscience Jounal, Uberlândia, v. 27, n. 4, p. 591-596, 2011.

KORNDORFER, G. H.; OLIVEIRA, L. A. Uso do silício em culturas comerciais. In: RODRIGUES, F. de A. Silício na agricultura. 5. ed. Viçosa: [s.n], 2010. cap. 1, p. 1-25.

KRAUSE, G. H.; WEIS, E. The photosynthetic apparatus and chlorophyll fluorescence: an introduction. In: LICHTENTHALER, H. K. (Ed.). Applications of chlorophyll fluorescence. New York: Kluwer Academic Publishers, 1988. cap. 1. p. 3-11.
LARCHER, W. Ecofisiologia vegetal. São Carlos: RIMA Artes e Textos, 2006. 532 p.

MADEIROS, L. B.; VIEIRA, A. O.; AQUINO, B. F. Micronutrientes e silício nas folhas de cana-de-açúcar: Escória siderúrgica aplicado no solo. Engenharia Ambiental, Espírito Santo do Pinhal, v. 6, n. 1, p. 27-37, 2009.

MELO, A. S. de; SUASSUNA, J. F.; FERNANDES, P. D.; BRITO, M. E. B.; SUASSUNA, A. F.; AGUIAR NETO, A. de O. Crescimento vegetativo, resistência estomática, eficiência fotossintética e rendimento do fruto da melancieira em diferentes níveis de água. Acta Scientiarum Agronomy, Maringá, v. 32, n. 1, p. 73-79, 2010.

OLIVEIRA, F. A. de; SILVA, M. N. B. da; OLIVEIRA, A. P. de; SANTOS, D.; PEREIRA, W. E.; OLIVEIRA, R. C. de; GONDIM, S. C. Efeito da irrigação e da adubação nitrogenada sobre algumas características de desenvolvimento do algodão colorido verde. Revista Brasileira de Oleaginosas e Fibrosas, Campina Grande, v. 12, n. 1, p. 49-57, 2008.

OLIVEIRA, F. de A. de; MEDEIROS, J. F. de; OLIVEIRA, F. R. A. de; FREIRE, A. G.; SOARES, L. C. da S. Produção do algodoeiro em função da salinidade e tratamento de sementes com regulador de crescimento. Revista Ciência Agronômica, Fortaleza, v. 43, n. 3, p. 484-492, 2012.

PAIVA, A. S.; FERNANDES, E. J.; RODRIGUES, T. J. D.; TURCO, J. E. P. Condutância estomática em folhas de feijoeiro submetido à diferentes regimes de irrigação. Engenharia Agrícola, Jaboticabal, v. 25, n. 1, p. 161-169, 2005.

POSADA, F. C.; OLMOS, J. E. P.; UlRICHS, C. Crecimiento y eficiencia fotoquímica del fotosistema II en plantas de fresa (Fragaria sp.) afectadas por la calidad de la luz: Implicaciones agronómicas. Revista U. D. C. A Actualidad \& Divulgación Cientifica, Bogotá, v. 14, n. 2, p. 43-53, 2011.

SANTOS, J. W. dos; ALMEIDA, F. de A. C.; BELTRÃO, N. E. de M.; CAVALCANTI, F. V. Estatística Experimental Aplicada. Campina Grande: Embrapa Algodão/ Universidade Federal de Campina Grande, 2008.

SÁVIO, S. L.; SILVA, G. C. da; TEIXEIRA, I. R.; BORÉM, A. Produção de biomassa e conteúdo de silício em gramíneas forrageiras sob diferentes fontes de silicato. Semina: Ciências Agrárias, Londrina, v. 32, n. 1, p. 103-110, 2011. 
SHIMAZAKI, K. I.; DOI, M.; ASSMANN, S. M.; KINOSHITA, T. Light regulation of stomatal movement. Annual Review of Plant Biology, Palo Alto, v. 58, n. 6, p. 219-247, 2007.

SILVA,M.M.P.da;VASQUEZ,H.M.;BRESSANSMITH, R.; SILVA, J. F. C.; ERBESDOBLER, E. D.; ANDRADE JÚNIOR, P. S. C. Eficiência fotoquímica de gramíneas forrageiras tropicais submetidas à deficiência hídrica. Revista Brasileira de Zootecnia, Viçosa, v. 35, n. 1, p. 67-74, 2006.
SUASSUNA, J. F.; MELO, A. S. de; COSTA, F. S.; FERNANDES, P. D.; FERREIRA, R. de S.; SOUZA, M. S. da S. Eficiência fotoquímica e produtividade de frutos de meloeiro cultivado sob diferentes lâminas de irrigação. Semina: Ciências Agrárias, Londrina, v. 32, n. 4, p. 1251-1262, 2011.

TAIZ, L. ZEIGER, E. Fisiologia vegetal. 5. ed. Porto Alegre: Artmed, 2013. 918 p.

TORRES NETTO, A.; CAMPOSTRINI, E.; OLIVEIRA, G. J. Photosynthetic pigments, nitrogen, chlorophyll a fluorescence and SPAD-502 readings in coffee leaves. Scientia Horticulturae, Amsterdam, v. 104, n. 2, p. 199209, 2005. 